Tatiana Bubnova

\title{
Medicina y literatura
}

Los últimos años del siglo $x v$, es decir, aquellos que tiempo después hemos identificado como los postreros de la Edad Media, quedaron señalados por muchos acontecimientos que fueron posibles gracias a los progresos tecnológicos y científicos que habrían de convertir el mundo en algo radicalmente distinto de lo que había sido por siglos y aun milenios. Los sucesos propiciados por aquellos adelantos y coyunturas quedaron registrados en la memoria colectiva como un verdadero parteaguas de dos épocas bien diferenciadas. Entre tales hechos, las transformaciones en las usanzas de la comunicación -relacionadas con la aparición de la imprenta - facilitaron el intercambio de ideas e información. Los avances en la navegación, cuyas consecuencias inmediatas fueron el desarrollo de las prolongadas y frecuentes travesías y el auge de los grandes descubrimientos geográficos, hicicron que cl mundo se abriera, se ampliara, sc volvicra más manejable. También el uso creciente dc las armas de fuego cambiaría pronto los patrones militares, permitiendo matar a distancia y con un rendimiento cada vez mayor, a pesar de que durante mucho tiempo después la ideología militar siguió enarbolando una mitología caballercsca, esencialmente medieval, basada en el valor, la destreza y la fuerza personal. Los combatcs librados por los curopeos con los indígenas americanos decidieron, dramáticamente, los des- 
tinos de vastas poblaciones. Dichas gucras fueron, en este sentido - y no sólo por las fechas_, batallas de la Edad Moderna.

Los hechos que se comentan ocurricron paralelamente a aquellos relacionados con cl redescubrimiento de las maravillas de la Antigúedad clásica, lo cual —atenićndonos a los límites cronológicos establecidos por la historiografía tradicionaldio lugar al nombre del primer periodo de la Edad Moderna: el Renacimiento. Pero junto con la serie de acontecimientos que resultan atractivos en las páginas de la historia, hubo otros, muy negativos, como la comparecencía y propagación de cnfermedades nuevas: consecuencia de las masivas migraciones internacionales, de las acciones bélicas a nueva escala y de los nuevos contactos y hábitos surgidos a fincs de la Edad Media y a lo largo del Renacimicnto.

Para España, en particular, tres han sido los hechos históricos que se hallan en el umbral que, convencionalmente, separa la Edad Media de la Edad Modema, y todos ellos cacn en el mismo año de 1492: lá expulsión de los judios españoles; la caída dc Granada, último baluarte árabc en España, y el "descubrimiento" del "Nucvo Mundo". Con este último succso, al que debcmos demasiado, se asocia también, aunque no sin disputas, el advenimiento dc un mal que asimismo inaugura, en cierto modo, la cntrada en la Edad Moderna. Se trata de una enfermedad que há sido uno de los terribles azotes de la salud humana; y todavía lo es, a pcsar de que en el siglo xx sc lograra aislar su agentc, encontrarle remedio y poncr, aparentemente, bajo control su propagación. Mc refiero a la sífilis.

Su irrupción tan inesperada y significativa, tanto para sus contemporáneos como para quienes reflexionarian sobre ella posteriormentc, se inscribía en el conjunto de las señales escatológicas. El contexto de su aparicion pone de manifiesto no pocas similitudes con cl padecimiento que ha sido la marca morbosa distintiva del presente fin de siglo y de milenio: el síndrome de inmunodeficiencia adquirida, o, por más scñas, cl SIDA. 
Fue en las postrimerías del siglo $x v$ que los médicos y los testigos describieron los síntomas de una terrible y desconocida cnfermedad, fatalmente contagiosa, torturante, vergonzosa e imposible de ocultar. Las primeras señales no eran sino cl inicio de una dolencia sin fin, la que habiendo empezado por afectar la piel y los órganos generativos, invadía posteriormente no sólo el cuerpo entero sino que afectaba también la mente. Nunca tcrminaba sino con la muerte. Los que tenían la desgracia de contraerla, quedaban desfigurados, lisiados $\mathrm{y}$, con los años, a menudo, dementes. La aparición de la nucva enfermedad fue interpretada como un castigo que Dios había enviado a la humanidad, sobre todo la curopea, por los infinitos pecados perpetrados en su contra, análogamente a la forma en que fue recibido el SWA al principio de su propagación, y antes del aislamiento del agente infeccioso que lo provoca.

Es difícil determinar con exactitud la fecha del arribo de la sífilis a Europa, continente en el cual adquirió proporciones epidémicas. Sus inicios aparecen cubiertos por la pátina del tiempo y difuminados por interpretaciones de conveniencia, las que en un análisis retrospectivo no siempre parecen tan evidentes como pretenden. Ahí donde historia, ciencia, filosofía y literatura se tocan, todavía espontáneamente - sin retraerse en campos autónomos y especializados-, las diversas interpretaciones se sobreponen una sobre otra, estorbando a la mirada científica en su búsqueda de los hechos de origen.

En el presente trabajo no será motivo de mi interés lo relativo a los matices puramente médicos del asunto, o sus implicaciones sociológicas. o incluso los variados procesos y hechos históricos influidos por la presencia dcl mal, sino más que nada los vínculos históricos existentes entre lo que para nosotros es, hoy, tan sólo "literatura", y la mcdicina, ciencia y arte cn la que la sífilis posee un lugar propio. Así, el mismo nombre actual de la enfermedad es, como se sabe, de origen absolutamente literario, porque fuc tomado de la obra de Girolamo Fra- 
castoro publicada en Verona en 1530. Aquí tampoco me voy a detener en las diversas anécdotas biográficas de los muchos literatos y artistas que la padecicron a través de la historia, talcs como Benvenuto Cellini, Ulrich von Hutten, Baudelaire, Nietzsche o, incluso, Schubert... Ahora bien, en los tiempos del inicio del trastorno fisiológico — cuando todavía carecía de nombre - se compusieron los primeros tcxtos médicos que describieron el mal. Eran el tipo de obras que, en cierta forma, asociamos ahora a la literatura o las estudiamos en su contexto, sobre todo aquellas versificadas, como es el caso del poema acerca de las "pestíferas bubas" de Francisco López de Villalobos (1498). Ya que sc trataba de un discurso médico, su autor hizo suya la tradición didáctica medieval, dimanada del Oriente, de moralizar y filosofar, además de transmitir los conocimientos rimados acerca de las cnfcrmedades.

Villalobos es recordado en la historia literaria española por haber cultivado la tradición epistolar, amén de que se le cvoca como poeta y traductor y comentarista del Anfitrión de Plauto. Resulta también interesante su posible relación con cl autor de $L a$ Celestina, durante su época de estudiante en Salamanca (Illades, passim). Sus tratados de medicina atraen la atención del investigador dentro del conjunto de su obra, considerada ahora, desde nuestro punto de vista, como un valor literario asi como una curiosidad filológica. Y no debemos olvidar su mérito para la historia de la medicina española, razón por la que dichos tratados fueron recuperados. En cambio, el Syphilis, sive de morbo galli$c o$, pocma latino del mencionado Fracastoro, no requiere de virtudes adicionales a las poéticas para ser rememorado; ocupa un puesto bien ganado en la historia de la literatura italiana pues posee, además de la información médica que suministra, indiscutiblcs méritos artísticos.

Entre estos dos autores situaré, oportunamente, El modo de adoperare el legno de India occidentale (1530) de Francisco Delicado, obra que expone un procedimiento curativo de la si- 
filis que fue válido hasta por lo menos el siglo xvin. ${ }^{1}$ Este tratado suele estudiarse como refucrzo fílológico - a veces sin hacer diferencia entre lo literario y lo médico- de su Retrato de la Lozana andaluza (¿1530?), obra literaria de ficción que contiene muy numerosas referencias al tema que en este momento nos ocupa.

Las tres obras mencionadas, publicadas, una en el límite de la Edad Media, y las otras dos en los albores de la Moderna, ocupan, de una o de otra manera, un lugar en la flexible frontera que había entre dos de las zonas de la cultura y del saber: la medicina y la literatura, campos que actualmente no solcmos confundir.

Tratándose de un tema semejante es inevitable, de cualquier modo, invocar problemas concernientes más a la historia de la medicina que a la de la literatura. En la anales de la sífilis predominan dos versiones acerca de los orígenes de aquella cnfermedad. Una de ellas asocia firmemente el descubrimiento de América con la aparición del mal en cl csccnario europeo. Según esta versión, la sífilis habría llegado al Viejo Mundo a bordo de las carabelas de Colon, cuyos navegantes regresaban de sus primeros viajes hacia las nuevas orillas alentados, según Fracastoro, por nova gloria mundi. Entonces, el inicio de la propagación epidémica de la enfermedad se fija en 1493-1494, más o menos. ${ }^{2}$ Existe la hipótesis de quc, hacia 1496, varias de

I Cf. Joaquin del Val, prólogo a su cdición del Refrato de la lozana andaluza. Madrid: Tauns, 1967, p. 18. Por cierto, la rcsina de la madcra del árbol Iropical guayaco, o guayacán (un sudorítico muy activo citado en El modo de adoperune... - cl cual sc siguió usando en América para aliviar la sífilis hasta ya cntrado el siglo $x(x-)$. aparece ampliamentc mencionado en el poeina de Fracastoro. Este hecho. junto con la aparición paralcla del tratado médico de Francisco Delicado y otros datos coincidentes. plantca un problcma histórico-literario respecto de las posibles relaciones entre ambos textos, tcma que aún no ha sido al parecer iratadn por los especialistas.

${ }^{2}$ Colón regresa a España del primer viaje el 31 de marzo de 1493 y trac consigo seis indios que supuestamente volvieron posteriormente. No hubo indicio alguno accrea de la enfermedad en los miembros de la tripulación. La segunda 
las mujeres traídas por Colón de las Indias Occidentales fueron a parar a los burdeles napolitanos. De ahí la fuente de uno de los primeros nombres difundidos que el padecimiento adquirió: el mal de Nápoles, ${ }^{3}$ que lo fue para los franceses, quienes contrajeron la cnfermedad en la campaña italiana -ocurrida de 1494 a 1495 - al penetrar en aquella ciudad durante la conquista del reino napolitano, guiados por el "cristianísimo" rey Carlos VIII. Y como los soldados galos contaminados diseminaron la novedosa afección por toda la península itálica, se le asignó por segundo nombre: el mal francés, o morbus gallicus. Delicado, en su tratado médico. evoca una leyenda acerca de las causas de la aparición del mal: fue una especie de castigo divino a las tropas francesas por haber atacado, camino a Nápoles, a los enfermos dcl hospital de San Lázaro en Rapallo (Génova). En los últimos años de la Edad Media nadie sabía aún de la cepa amcricana de la Syphilis, así que la sanción divina por la rapiña militar era una cxplicación aceptable y satisfactoria.

La versión del origen americano de la enfermedad fue muchas veces debatida, a veces con un afán incluso patriótico, pero jamás desechada definitivamente. ${ }^{4}$ Por otra parte, no olvidemos cl singular y, a su modo, justo comentario de uno de los historiadores novísimos de la cuestión:

expedición regresa en junio de 1496, cuando la epidemia sc había manifestado desde hacía más de un afio. Pero al parecer hubo un par de viajes intermedios comandados por Antonio de Torres, quien trajo a España, en el transcurso de 1494, a veintiséis indios de ambos sexos, y a cerca de trescientos en la primavcra de 1495 (cf. Quétel, Hisrony of Syphilis, pp. 43-44).

3 Asimismo, la cnfermedad solía llamarse, en las primeras etapas de su dcscubrimiento y propagación, bubas pesilíferas, pestilencia, pox, plaga, elefantia. plaga cgipciaca, entre otros nombres.

4 Una de las soluciones "diplomáticas" a la paternidad de la enfermedad es la del ya mencionado Joaquín dcl Val: "La plaga brotó con fuerza en Ńápolcs, en 1496, y se extendio por Italia. Alcmania, Francia y España. Al mismo tiempo los navegantes españoles crcontraron una enfermedad semejante en la isla dc Santo Domingo". El retrato..., p. 20. Como veremos, Fracastoro muestra una postura semcjantc ante cl problema. 
However, there is no reason why the New World, which was ravaged by smallpox, measles and diptheria imported from Europe (all of which erupted with the same force as did syphilis in Europe), should have had nothing to give us in return. Was it perfectly isolated as far as infectious deseases were concerned, as is frequently asserted by those who pursue the infant story of historical epidemiology? The New World may still pass for an island, but it is, after all, a whole continent... (Quétel, History of Syphilis, p. 44).

Sin embargo, otra opinión sosticne que la sífilis es un mal que siemprc ha cxistido en Europa, y que adquirió proporciones de epidemia debido al cambio drástico de las condiciones sociales y los hábitos y conductas de la población a fines del siglo $x v .{ }^{5}$ Con el fin de avalar sus puntos de vista, los adeptos de cada una de ambas versiones han recurrido, curiosamente, a la supucsta cvidencia contenida en huesos prehistóricos. Con ello realizan sendas demostraciones de que la enfermedad ya existía en la edad de piedra, tanto en Europa como en América.

El hecho es que todavía cn cl primer tercio del xv el morbo gálico no siempre se vinculaba definitivamente con los viajes de Colón. Así, Delicado, basándose supuestamente en Femández de Oviedo (de cuya obra habría tomado la descripción formal del principio medicinal del guayaco), declara que en las Indias existía una enfermedad parecida, aunque de efectos mucho más livianos, y que tenía cura gracias al aludido medicamento. Los marineros españoles empezaron a importar este remedio de las islas del Caribe a Europa, el cual tuvo un determinado prestigio durante cierto tiempo. ${ }^{6}$ No obstante, el mismo Fermández de

${ }^{5}$ Este es uno de los variados rasgos que asocian el escenario social de la aparición de la siffilis con las características, análogas, dcl SIDA.

6 Dice Delicado: “...navigandosi da li nostri spagnoli a molte isole postc nel'ocidente, dicto mondo novo, cioe l'isola di San Dominico, l'isola Beata, l'isola Isabcla, ne le qual quasi simile malatia ritrovasi, cioè di natura di clcphantia. Et essendo alquanti spagnoli infetti de bulc, quasi simile a la clephantia, credendo 
Oviedo, ${ }^{7}$ igualmente que otros autores - como, por ejemplo, Díaz de Isla, Las Casas y, más tardc, Gabricllo Fallopio, que se reficren tempranamente a esta enfermedad-, inequívocamente señalan su origen americano.

Ahora bien, tanto de las fuentes literarias como médicas do la ćpoca se puede obtener un dato interesante: algunos autores, como Delicado, sitúan la aparición de las "bubas pestíferas" en 1488 , en una - señala éste- de las campañas italianas de los franceses. Así, en el mencionado El modo de adoperare el legno de India occidentale... Delicado escribe:

Cosi come al tempo de Tiberio Cesare, terzo imperatore d'i romani, nacque vna cgritudine chiarnata lichenc, e per auanti, al tempo di P'ompeio Magno, aparue la infirmità elephantia, sic da li medici nominala, così nel anno 1488, in Rapalo de Zenova, comenzaron le broze nel'exercito del christianissimo Carlo, re di Francia (257). ${ }^{8}$

quelli insulari indiani che fosse quella istessa malatia che loro qualche volta, o quasi semper patiscono, li mostrorno questo arbore..." (El modo..., ed. Damiani, p. 258).

${ }^{7}$ Dice Fernández de Oviedo: "La primera vez que aquesta enfermedad en España se vio fue despues que el almirante don Cristóbal Colón descubrió las Indias y tomó a esias partes, y algunos cristianos de los que con él vinieron que se hallaron en aquel descubrimiento, y los que en segundo viaje hicieron, que fueron más, trajeron esta plaga, y de cllos se pegó a olras personas; y después, cl año dc 1495, que el gran capitán don Gonzalo Fernández de Córdoba pasó a Italia con gente a favor del rey don Fernando joven de Nápoles. contra el rey Charles de Francia, el de la cabeza gruesa, por mandado de los Católicos reyes don Femando y doña Isabel. de inmorlal memoria, abuclos de yucsıra sacra majestad, pasó csta cnfermedad con algunos de aquellos españoles, y fue la primera vez que en Italia se vio; y como era en la sazon que los franceses pasaron con el dicho rey Charles. llamaron a este mal los italianos el mal francés, y los franceses lo llamaron mal de Nápoles..." (Sumario..., pp. 220-221).

${ }^{8}$ A este propósito, el siguiente pasaje del poema de Fracastoro, tomado de la primcra parte. donde se describe justamente el origen. la sintomatología y los remedios contra esta enfermedad, merece ser citado:

Sic elephas sacer Ausoniis incognims oris.

Sic lichen latucre diu, quibus accola Nili

Gens lantum, regioque omnis vicina laborat (Ed. Ramlrez, p. 20). 
Empero, algo no está bien en la información que maneja Delicado, ya que la invasión de Italia a manos de Carlos VIII de Francia sc inicia en 1494, y no en $1488 .^{\circ} \mathrm{Y}$ el autor insiste: en otro lugar (en La Lozana andaluza) indica que "cuando vino el rey Carlo a Nápoles, que comenzó el mal incurable el año de mil y cuatrocientos y ochenta y ocho..." (CA 85, p. 421).

Esta fecha, a la vez que permite disociar la llegada de la enfermedad a Europa con los viajes de Colón, en el contexto de la obra cle Delicado aparece enlazada -diríamos. ideológicamente marcada - con otro acontecimiento de connotaciones nefaslas. De acuerdo con los personajes de La Lozana andaluza, aquel mismo año de 1488 "se puso la Inquisición" en Andalucía. Así, los efectos de la enfermedad quedan asociados, en el universo semántico del autor, a la nueva arremetida de las persecuciones oficiales contra los judíos españoles, uno de los cuales, si bien converso, pudo haber sido el propio Francisco Delicado. ${ }^{10}$

El origen de la enfermedad, según Delicado - amén del hipotético castigo a la impicdad de los franceses cuando maltrataron a los enfermos de San Lázaro-, estaba ligado a la resistencia que los napolitanos cxteriorizaron a las tropas francesas: la población rebelde, con el fin de perjudicar a los invasores franceses, supuestamente alteraba cl vino con cal, lo cual provocaria la enfermedad. No obstante, es la explicación sobrenatural la que prevalece y antecede a cualquier racionalización de las causas. Así está en el tratado de Villalobos, en Delicado y también en el más fantasioso de todos: el de Girolamo Fracas-

- Cf. las ediciones de B. Damiani (Castalia 1969, p. 351): de G. Allcgra (Taurus 1983, p. 323) y la de Allaigre 1985, p. 421.

${ }^{10}$ La verdad cs que Delicado se equivoca, tanto en fechar la campaña italiana de Luis VIII, como en el establecimiento de la lnquisición, que fuc en 1480 (documentos de procesamiento de judaizantes en Córdoba que sc rcfieren a 1482). Lo significativo aqui es cómo entendía los aconcecimientos histuricos, poniendo en una misma cadena la Inquisición, la invasión francesa de Iralia y el advenimiento de la cnfermedad. 
toro, que además construye toda una mitología latinizante en tomo a la cnfermedad de las bubas.

En los textos españoles, esta interpretación se remonta al ya mencionado poema Tratado sobre las pesifferas bubas escrito por el médico Francisco López de Villalobos en 1498, el cual se halla incluido en un compendio de su autoria intitulado Sumario de la medicina. Es evidente que, dados los alcances y la virulencia de la enfermedad, su descripción y eventual tratamiento merecieron, en aquella época tan temprana, un lugar aparte dentro del manual médico del galeno español. De acuerdo con la dedicatoria, la composición del Sumario está relacionada con cl primer empleo oficial dcl nucvo doctor, recientemente graduado por la universidad de Salamanca. Los especialistas actuales señalan el carácter sistemático, racionalista y, para su tiempo, avanzado de la obra, en la que sin embargo todo el sistema de descripción, explicación y tratamiento de las diferentes enfermedades se basa en la antigua teonía galénica de los cuatro humores la que, por cierto, no perdería terreno en la medicina todavía durante un buen trecho histórico.

Así pues, en el tratado "Sobre las contagiosas y malditas bubas: estoria y medecina", el "licenciado de Villalobos" describe:

Fue una pestilencia no vista jamás

en metro ni en prosa, ni en sciencia ni estoria...

Es muy gran vellaca, y así a començado por el mas vellaco lugar que tenemos. ${ }^{\prime \prime}$

El autor organiza la descripción de la dolencia de acuerdo con la jerarquia de las "causas" que supuestamente la suscitan, procediendo de las generales a las particulares; las presenta con

11 Afgunas obras del doctor francisco Lbpez de Villalobos, publicadas por Antonio María Fabic (Sociedad de Bibliófilos Españoles, vol. XXIV, Madrid. Imprenta de Miguel Ginesta, 1886. pp. 452-453). 
la siguiente terminología: "universales y cquívocas" e "inferiores y extrínsecas", así como "antecedentes y conjuntas". Entrc las primeras, la que prevalece es desde luego la teológica, hasta el punto de que el autor "habla en la persona de Dios" al dirigirse al género humano, reprochándole cl mal uso que le ha dado a las potencias que el Todopoderoso le otorgó. En virtud de la mala conducta de los mortales, se les envía un ángel apocalíptico que hiere, por medio de la enfermedad, al inocente y al culpable: pecando los príncipes, pagan los súbditos. Otra opinión teologal es que "qual cs cl pecado tal la penitencia", debido a la lujuria extendida por todos los estados. Se aducen ejemplos bíblicos y, con hase en cstos paralelos, al mal todavía sin nombre definitivo se le asigna el provisional de la "plaga egipcíaca", recordando que el Faraón prendado de Sara cae herido por Dios "en su natura" —dice Villalobos-, "daquesta passion o de otra como ella" (entiéndase, de otra enfermedad venérea). Muestra un intcresante cambio en las conductas sociales que recuerda la época inicial del SIDA: "los hombres tomados / tan castos, que no osan llegar a muger".

A la causa universal teologal le sigue la astrol6gica: la maligna conjunción de Saturno (muerte) y Marte (guerra). Después siguen las consideraciones históricas, gcográficas, climatológicas y, lucgo, la teoría de los cuatro humores, de acucrdo con la condición particular de los cuerpos: "humores adustos en higado y vena", presencia del "flema salado", descomposición general del equilibrio de los humores.

En su concepción de la cicncia, Villalobos se basa en una teoría integral del funcionamiento del cuerpo, que es justamente la de los humores, que por antigua que fuera, es desarrollada por el médico castellano en una dirección racionalista, y propone asimismo una cura integral. Su tratado Sumario de medicina cs a la vez, catálogo de enfermedades scgún Avicena, manual para médicos principiantes y libro de consulta para los "letrados de otras facultades". 
Específicamente sobre las "bubas", Villalobos describe los tratamientos que estarfan vigentes, cn términos generales, hasta bien entrado el siglo $\mathrm{xx}$, como acjuel que incluye el del uso del mercurio ("azogue"), y las dictas afincs a aquellas que desarrollaría Delicado en su tratado sobre el "leño de Indias". Cervantes, en el Cologuio de los perros, hace referencia a dietas y tratamicntos similarcs. ${ }^{12}$ Hay alusiones a una concepción semejante del tratamiento de este mal en Vida y hechos de Estebanillo González. Sin duda alguna se trata de un dato histórico de consideración, que es igualmente recurrente en las obras especializadas en otros idiomas.

Pese a que Villalobos es conocido en la historia literaria española como un escritor chocarrero, en su obra estrictamente especializada, el Sumario de la medicina, se mantiene dentro de una clara seriedad profesional (con alguna excepción aisla$\mathrm{da}$, como veremos enseguida). Las referencias posteriores que hace de la mcdicina, cn sus obras de carácter literario, ${ }^{13}$ se encuentran plenas de aspectos jocosos y jocoserios. Del mismo modo, la enfermedad que nos interesa se inscribe, en el conjunto de la obra de Delicado, en un contexto que le da, a pesar de todo su patetismo y el auténtico dolor no ficcional, un valor cómico-serio. El "mal francés" aparece asociado a la alcgre y despreocupada sexualidad, cuya percepción en aquella época todavía no se desvincula del todo de la cultura popular de la risa y de la concepción carnavalesca del mundo. Por otra parte, el "mal francés", que es a su modo una especie de "mal de amores" (casi amor hereos), cs un mal venéreo que cn cl contexto de Delicado no adquiere todavía toda la connotación siniestra que sin duda mercce, y que le darían otras épocas.

12 Se recomiendan en general dietas ligeras de nutrientes secos. Delicodo in. siste en las frutas secas. nueces, pasas. frente al cfecto purgante de la infusión del teño salutifero. El eco del tratamiento se pucde encontrar en Cervantes.

13 Véasc su cpistolario. que incluye algún diálogo. El carácıer literario de las cartas de Villalobos fue pucsto de relieve por Márque?, Villanueva. y estudiado con mayor detalle por Beth Tremallo. 
Por otro lado, el amor hereos, mal de amores, posee un estatus de enfermedad como cualcsquicra otras a fines de la Edad Media, pero su tratamiento carece de la seriedad con que los doctores tratan los padecimientos estrictamente corporales, aunquc estuviese relacionado con la tcoría de los humores. Por cierto, el hecho de que Villalobos lo incluyera también en el Sumario confirma su clasificación como padecimiento común producido por la comupción de la mente; y el tratamiento, que corresponde a toda una litcratura universitaria de final de la Edad Media, ${ }^{14}$ no lo hace ajeno a los aspectos jocoscrios. En cuanto castigo por los pecados y en cuanto resultado de las siniestras conjunciones astrales, el mal de las bubas posee características afines al amor hereos. Pero, en su postura de médico, Villalobos se acerca a las intuiciones más modemas acerca del origen y terapéutica de las enfermedades contagiosas y epidémicas.

Ahora bien, el castigo siniestro que constituye en la vida real el mal venéreo de las "bubas pestíferas" admite, debido al distanciamiento literario, aspectos irónicos, jocosos e inverosímilmente gozosos en las obras cuyo objetivo es más artístico que médico, tal como lo hace Delicado en el Retrato de la Lozana andaluza. Otro autor que se permite tratar la temible sífilis desde una postura jocoseria integral es, como sabemos, Maître François Rabelais. Esta contradicción - literariamente cancelada - cntre dolor y placer habrá de desaparecer paulatinamente de las obras artísticas con la implantación del criterio de "buen gusto", por una parte, y con una decidida inclinación del tratamiento del tema de la enfermedad hacia el punto de vista satírico, por otra. Así, un caso de transición de lo jocoso a lo satírico lo podemos encontrar en las obras de Scbastián de Horozco (Coplas) y en parte en Gaspar Lucas Hidalgo (Diálo-

1s Cf. Pedro Cátedra. Amor y pedergogio en le Edad Media. Sajamanca: Universidad. 1986. 
gos de apacible entretenimiento), entre los no pocos autores del xvi que incurrieron en cl tema.

En la obra de Delicado, quien fue víctima de la enfermedad de marras, la protagonista de su Retrato hace caso omiso de los efectos dolorosos y repugnantes del mal que evidentemente padece, a pesar de que ostente una scñal inequívoca -una "estrellica" en la frentc- que ha sido interpretada como estigma develador de su condición perniciosa. ${ }^{15}$ La enfermedad no impide que ejerza exitosamente el sexo, incluso con fines lucrativos. Ha sido justamente señalado el estatus alegórico del Retrato, en el cual su heroína enferma se eleva al símbolo de la corrupción romana. ${ }^{16}$ No obstante, todas estas observaciones son justas tan sólo parcialmente. En el contexto de la obra, la Lozana es alguien que sobrevive en condiciones adversas gracias a su vitalidad en plena medida relacionada con el sexo, cualidad y actitud que además comparte con todo su entorno social, del que no es sino parte legítima. Y el reconocimiento del ascendente del sexo sobre la existencia humana como algo natural y libre de culpa es uno de los aspectos de la obra de Delicado que hasta ahora no ha sido convincentemente interpretado, a pesar de la obvia contradicción con la moral cristiana que la obra supuestamente ostenta. Lozana sí es símbolo de la corrupción moral de todos, especialmente de la Roma papal (aspecto que puede reconocerse como paraerasmista), pero al mismo tiempo es símbolo del gozo de la vida a través del sexo, faceta que sc aleja suficientemente del cuasi protestantismo de la crítica erasmista en torno a los pecados de la curia (por ejemplo, los hermanos Valdés). En este sentido, la religiosidad del Retrato, proclamada casi por unanimidad como total y tradicionalmente cristiana y aun precontrarreformista, se declara más bien como judía o simplemente semítica (o averroísta), lo

15 La cdición que cito (Allaigre, 1985), sc basa, a su vez, en un trabajo antcrior sobre cl tcma de C. Allaigre: Sémantique et littérofure. Grcnoble, 1980. 
cual hace un interesante contrapunto entre lo que el texto de Delicado pretende decir en su apariencia (mediante todos sus ancxos y rectificaciones) y lo que realmente dice (en el texto y en los mismos anexos). Así, la sífilis, no marcada aún con csta tcrrible palabra - tal y como sucna al público de este siglo-. está tratada con una ambivalencia carnavalizada. Es ésta la que le permite a Delicado expresar una crítica $\mathrm{e}$ inclusive una cuasi sátira política, sólo que la evanescente línea divisoria entre burlas y veras no se traza ahí donde habitualmente la crítica la encuentra, sino que está justamente en conflicto con cl sentido general de la crítica de tipo erasmista. Ahora bien, esta contradicción no es de carácter antagónico ni absoluta, sino que cuestiona - de rebote - los efectos políticos y existenciaies de la interpretación erasmista del suceso histórico real, incluido a título de recapitulación en la obra de Delicado. Un castigo divino por los pecados de la curia y los de todos los romanos culpables o libres de culpa, según Alfonso de Valdćs, fue el Saco de Roma de 1527 por las tropas imperiales. Delicado no cs reacio a admitir la justeza de tal actitud y, más aún, se adhiere a ella en una aparente alabanza a la política imperial. Sin embargo, es evidente que para él resultan bien visibles los instrumentos en sí comuptos de esta "justicia divina": los lansquenetes del empcrador, en un gran porcentaje protestantes, se dedican a la rapiña y al asesinato de los pobladores... ¿en nombre de Dios? En este aspecto, la actitud de Delicado frente al Saco coincide bastante con una serie de obras españolas e italianas que describen el nefasto suceso. Tanto en el literario Retrato, como en el especializado Modo de adoperare el legno..., está sin duda presente esta actitud participativa y crítica hacia los efectos de la política imperial sobre la población.

En El modo de adoperare el legno de India Occidentale, su tratado más especializadamente médico — pero que aun así conserva una parte de la irónica ambivalencia del Retrato-, Delicado conserva el orden de la descripción que encontramos 
en Villalobos: fija las causas teológicas y astrológicas prácticamente en los mismos términos que Villalobos, e incluso asienta precedentes tomados de la Biblia y de la historia de la antigüedad clásica según los mismos cjemplos. Así, menciona también la "elefantina" o "elefancía" y la "plaga egipcíaca", de modo que es posible suponer, o una consulta previa del tratado de Villalobos, o la consideración de otras fuentes que toman en cuenta a aquél. ${ }^{16}$ Ahora bien, Delicado es el único que menciona el caso de Rapallo: la ofensa infligida por los franccses a los enfermos de san Lázaro. La consecuencia es también teológica: la enfermedad como castigo divino inmediato (recuérdesc de cómo Villalobos "habla en la persona de Dios"). Ahora bien, el Saco de Roma es un castigo análogo a la sífilis por la depravación generalizada.

Después de las causas "teológicas", aparecen las "históricas" y "materialcs", como el posiblc cnvenenamiento de los pozos y la alteración del vino.

Por lo demás, un esquema semejante de presentación de la enfermedad y de su cura se encuentra también en otros tratados, entrc cllos en el poema dc Girolamo Fracastoro. En el texto vienen luego el régimen, las dietas y las sugerencias astrológicas para las dietas, y aparecc reproducido un capítulo de la Historia natural de las Indias, de Gonzalo Femández de Oviedo.

Pascmos, pues, a Fracastoro: la medicina y la literatura se dan la mano a propósito del "mal francés" cn una obra más - publicada prácticamente el mismo año que la de Delicado (Ugolini 1975) -, cuyos propósitos no perteneccn estrictamente al campo cognoscitivo y práctico de la medicina, o al educativo y de diversión de la literatura, sino a los dos simultáneamente. La obra fue escrita en versos latinos, cn una época absolutamente paralela a la de las actividades literarias y paramédicas de Deli-

16 Acerca del posiblc contacto de Delicado con la obra de Villalobos, hago ciertas conjenras en mi trabajo "Villalobos y Delicado" (ponencia presentada en el congreso de la A. I. S. O. de 1999, en Munster; en prensa). 
cado, cn Verona - tan próxima a Venecia-, y sc gesta en un ambiente que posiblemente logrará rozar, aunque no muy profundamente, el autor andaluz.

La obra se divide en tres partes. En la primera se brinda la descripción de la enfermedad en el contexto contemporáneo de división interna de Italia, gucrras intestinas e invasiones cxtranjeras, acompañadas de infinitos daños a la población. También se proponen las dietas y remedios comunes. La segunda parte está dedicada a las bondades de las curas mcrcuriales, para lo cual Fracastoro construye una primera mitología en torno al pastor Ilceo, que sufre de la enfermedad por haber cometido el sacrilegio en contra de Diana. La ninfa Lipare le enseña cómo pacificar a la diosa y cómo curar su cuerpo, y lo lleva a un viaje subterráneo donde le muestra todo un universo de mineria atendido por las ninfas dedicadas, entre otras cosas, a la fabricación del oro a partir del azufre y el mercurio. Un río de mercurio será fuente de salvación para Ilceo. La terccra parte, escrita más tarde y por sugerencia de Bembo, amigo y paisano de Fracastoro, introduce el tema del guayaco y glorifica el descubrimiento de América.

Hay un indudable paralelismo entre el mito situado en Europa y aquel mediante el cual Fracastoro explica la presencia de la enfermedad en Amćrica: Ilceo/Sífilus, Diana/Dios del Sol, mercurio/guayaco, sacrificio propiciatorio en ambos casos. El equilibrio axiológico entre las realidades de las dos partes del mundo, si bien especulativo y utópico, posee una carga profundamente positiva.

Sífilus, un pastor que comete un sacrilegio sin advertirlo, padece un cruel castigo del dios del Sol, en forma de una terrible enfermedad (adivinen cuál), y encuentra una cura gracias a la ninfa llamada América y a las bondades del salutífero árbol del guayaco. Hemos visto en el tratado médico de Villalobos que el mercurio figura ya entre los remedios efectivos contra el mal, y que el guayaco es el centro del mćtodo curativo que propone Delicado. 
El origen del extraño nombre de la ninfa salvadora de llceo - Lipare - se encuentra tal vez, razonablementc, al confrontar el Retrato con el pocma de Fracastoro. Al final de su obra, Delicado incluye una casi inexplicable, y en todo caso inesperada, referencia a la Isla de Lípari, adonde la pecaminosa heroína planea retirarse para encontrar la paz después de su tan accidentada vida. Ahora bien, Lípari (la isla principal del archipiélago de las islas Eolias o-de Lípari-, situado en el mar Tirreno, al sur de Italia) es una ínsula casi desierta y considerada inhóspita, a tal punto que al parecer fuc dcsde antiguo lugar de deportación de delincuentes. ${ }^{17}$ Precisamente, el confinamiento en esa isla constituia un fin muy instructivo y ejemplar para una vida non sancta. Pero, por una parte, cabe suponer que en esta caracterización de Lípari las interpretaciones valorativas sean anacrónicas, y, por otra, no debemos menospreciar las connotaciones culturales de mayor antigüedad, sin duda más familiares para los autores que estamos tratando.

Resulta que las asociaciones clásicas de las particularidades de Lípari nos aportan datos de otra índole: "Le Eolie durante l'epoca romana furono un luogo di delizie frequentato come stazione termale e furono sfruttate anche industrialmente per l'allume ${ }^{18}$ che in esse si produceva", informa la Enciclopedia Italiana, ${ }^{19}$ la cual evoca también un clima salubre y muy suave, con los fríos invernales y los calores estivales mitigados por la influencia del mar. Más allá de las apreciaciones subjetivas 0 pretendidamente referenciales en torno a las islas Eolias, cabe recordar que más de una novella del Decameron tienc por escenario a Lípari, lo cual confirma la habitabilidad literaria del mencionado topos.

17 Éste hecho ha sido destacado por investigadores contemporáneos que se apoyaron en datos corrcspondientes a la época de Mussolini.

18 Allume: Alumbre (sal blanca y astringente).

${ }^{19}$ Enciclopedia Laliana, s.v. Lipari. 
Lo que la cnciclopedia sí aporta en datos útiles, es el hecho de que, curiosamente, Lípari tambićn era lugar dc minería, aunque no he podido constatar que de allí se extrajera mercurio, lo que más viniese al caso en relación con nuestro tema: este mineral, al parecer, se producía en las bien conocidas (por el informe dc Mateo Alemán, famoso autor del Pícaro, libro del que fue precursor cl Retrato de la Lozana andaluza) minas de Almadén, en España.

Pcro en el poema de Fracastoro, la ninfa Lipare conduce al enfermo pastor Ilceo por los corredores subterráneos de las minas en las que unas ninfas trabajan en la extracción de metales y otros minerales, y en la confección del oro (mediante la mezcla del azogue con el azufre); el azogue (mercurio) será el remedio para la cnfermedad:

Nocte deae et Tellure satae, queis munera mille, Mille artcs, Studium est aliis deducere rivos, Scintillas aliis rimari, et sparsa per omnes Semina tellurem flammarum; ignis que corusci. Matcriam miscent aliac, massamque cocrcent Obicibus, multa et gelidarum inspergine aquarum.

Non procul eruptis fumantia tecta caminis Aetnaei Cyclopes habent, versantque coquuntque Vulcano stridente, atque acra sonantia cudunt. Lacva haec abstrusum per iter via ducit ad illos. Dextera sed sacri fluvii te sistet ad undum, Argento fluitantem undam, viroque metallo Unde salus speranda. Et iam aurea tecta subibant, Rorantesque domos spodiis fuligineque atra Speluncas varie obductas, et sulphure glauco. Jamque lacus late undantes, liquidoque fluentes Argento juxta astabant, ripasque tenebant. ${ }^{20}$

20 "Aquí habitamos infinitas diosas hijas de la Noche y de la Tierra cjerciendo mil funciones difercntes. Las unas están ocupadas en conducir por canales el agua necesaria para los trabajos; otras están encargadas cn reunir de todas las partes de 
Fracastoro (1482-1553), gran humanista, escribe su poema en un latín virgiliano, y el texto está repleto de refcrencias clásicas de todo tipo. Además, el autor fabrica nuevos mitos, como ya he dicho, sobre la sífilis y otras cuestiones (como el descubrimiento de Amćrica y el "encuentro de dos mundos", como diríamos ahora), ${ }^{21}$ tomando como base cl modelo antiguo y clasicizante.

Para la fecha de publicación del poema, en el Nuevo Mundo ya se han dado los primeros hechos esencialcs de la Conquista y sc ha establecido el cstilo del dominio español sobre los nuevos territorios. Hace años había caído ya la gran Tenochtillán, aunque la "visión de los vencidos" permanecería solapada durante siglos ante Europa. La fascinación en torno a la apertura de las fronteras arcaicas impuestas al mundo por la cosmovisión medieval, aunada a un desconocimiento total o parcial de cómo se desartollaban los hechos de la Conquista, le permi-

la tierra las particulas de fuego que cntran en la composición de los metales: aqueIlas tienen la comisión de hacer las mezclas y de dar forma a las materias enfriándolas con cl rocío de heladas aguas. No lejos de este lugar. los cíclopes del monte Etna han fijado su terrible fragua, de donde salen torbcllinos de humo y de fucgo cuando revuelven y ablandan los metales para labrarlos. El camino que ves sobre la izquicrda conduce a su morada por una senda estrecha y diffcil; mas cl que está a la derecha nos llevará a un río sagrado de metal líquido que parece ser de plata animada, de cuyas ondas debes esperar la curación. Entre tanto penetraron en unos subterráneos cuya hoveda dorada cstaba cubierta de las ccnizas de los metalcs. de un hollín negro y de un azufre verdoso, y al punto se hallaron en la ribera de un río que se dilataba extensamentc, y cuyas olas se deslizaban como plata líquida" (Trad. Ramirez, p. 85).

${ }^{21}$ En la tercera parte de su poema Fracastoro describe cómo los españoles de Colón llegan a las Indias, conocen la cnfermedad, el remedio y el rito mediantc cl cual se efectúa la cura. Les cuentan el mito de Síílus, y "Entre tanto, al gunas naves que se habian dado a la vela para las costas de Europa y hablan vuelto atravesando los anchos mares (;Oh decretos impenetrables de los dioses!), contaron que la misma plaga infestaba el aire de Europa y llevaba la desolación a todas las ciudades, atónitas con eslé nuevo azote para el que no se encontraba remedio. Una nucva todavia más triste se propaga por las naves: que la enfermedad ha invadido la flota, y que la mayor parte de los Españoles la padecen". La Syphilis, poema latino de Gerónimo Fracastor, traducido al castellano e ilustrado con notas por D. Luis María Ramírez y de las Casas-Deza... Madrid, Imprenta de Jose M. Ducazal, 1863. p. 119. 
ten a Fracastoro amar una especie de utopía en torno a un encuentro no real, sino posible y descable entre dos mundos, dos culturas, utopía basada en modelos clasicizantes y humanísticos y en la idea implícita accrca de la unidad y la igualdad del género humano. Dioses análogos a los romanos rigen los horizontes americanos; una monarquía scmejante a la europea organiza el mundo social, y la relación entre los recién llegados y los dueños legítimos de las tierras americanas se desarrolla de acuerdo con las reglas de la estética caballeresca, esto es, esencialmente medieval, aunque inserta en un marco clasicizante. Desde una cicrta perspectiva contemporánea, Fracastoro tal vez merezca un reproche por haber concebido una visión eurocentrista sobre los asuntos americanos. Así, para relacionar los conceptos de Europa y América, introduce los datos de Platón sobre la Atlántida.

Scgún Fracastoro, los espan̄oles de Colón llegan a las Indias, conocen a sus habitantes y a sus soberanos, conocen la cnfermcdad y los mitos relacionados con ella (el mito del "pastor siniestro" Syphilus), así como cl remedio para curarla. Los indígenas americanos adoran al Sol y cl remedio sagrado del guayaco. Interrumpiendo un ritual indígena, llcgan en sus barcos los europeos, todos enfermos de bubas, y encuentran el remedio del árbol santo. Se llevan la milagrosa medicina del guayaco (Hyacum), y al volver a Europa se cnteran de que toda una epidemia sc ha manifestado, en la forma de una enfermedad mucho más severa que la que hallaron en América. Un cuadro, pues, esencialmente análogo al que traza Delicado en su tratado sobre el mismo leño, publicado, reiteramos, el mismo año que el poema del humanista italiano, y en la misma región vćneta.

Es vasto el cuadro de desgracias que padece Italia desde los fines del siglo xv hasta la época: invasiones extranjeras, discordias civiles, hambre, latrocinio, pillaje, destrozos y enfermedades son un género de desdichas que acompañan gereralmente a 
las guerras, ${ }^{22}$ entre las cuales el surgimiento de la epidemia sifilítica aparece como la última gota para colmar la plenitud de las desventuras. El lamento poético constituido en un cuadro clasicizante posec matices escatológicos debido a los cuales la aparición de la enfermedad se pinta como una plaga apocalíptica (rasgo medievalizante), llevando como paralelo la gloria del descubrimiento del Nuevo Mundo y la ampliación de los horizontes alcanzables del Viejo (rasgo renacentista):

Si ha aparecido una dolencia desconocida, si hemos padecido crueles guerras, si hemos visto las poblaciones inundadas con la sangre de sus habilantes, y entregadas a las voraces Ilamas, los reinos destruidos, los templos anasados, y profanados los altares; si hemos presenciado las inundaciones de los ríos que han desolado los campos, arrancado las arboledas y arrebatado en su corriente las cabañas, los ganados, y los pastores; si, en fin, el hambre ha sucedido a tantas calamidades, ¿no se ha visto también en esta edad lo que se había negado a los siglos anteriores, que nuestras naves recorriesen la inmensa extensión de los mares que Anfitrite comprende en su vasto seno, y que fueron una barrcra insuperable a nuestros antepasados? ${ }^{23}$

El orgullo por la humanidad como un todo, la fascinación por la nueva apertura del cuadro del mundo, la nueva confianza en las potencias del hombre y la explicación del mundo en función del ser humano (antropocentrismo) agregan a la visión milcnarista y teológica este aliento optimista que identificamos con el Renacimiento. De tal simbiosis deviene la extraña obra humanista de Fracastoro, que, entre muchas otras visiones ideologicas, marca un verdadero umbral entrc las dos Edades. En el

22 "¡Desgraciada ltalia! ¡he aquí cómo la discordia te ha despojado de tu antiguo valor y del imperio del mundo. patrimonio de nuestros mayores! ¿Hay alguna de tus comarcas que no haya experimentado los horrores de la scrvidumbre. los latrocinios de la gucra y las más funestas morlandades?" Traducción de Luis Ramirez de las Casas-Deca, ibid., p. 45.

23 Ibid. pp. 51 y 53. 
optimismo inherente a esta visión, las marcas semánticas que en otro contexto constituyen una alegoría de guerra y muerte (Martc-Satumo, como en Delicado), o remiten a un cuadro astrológico, en el suyo, mediante una reinterpretación clásica, significan al mismo tiempo una genealogía gloriosa y una apelación plena de esperanzas:

Dii patrii, quorum Ausonia est sub numine, fuque

Tu Latii Satume pater, quid gens tua tantum

Est merita? ? $^{4}$

Si bien el tratado médico del cura español es sin duda un texto especializado, cuyo propósito es proporcionar una ayuda médica a los pacientes, su texto comparte rasgos con miscelánea literaria. Y aunque el texto del veronés se centra en la enfermedad como tema, y pese a quc algún capítulo - por ejemplo, de la segunda parte - puede servir como verdadero tratado de epidemiología científica, la fabulación literaria, el canon clásico y el uso extendido del discurso figurado apartan su texto, al menos para nosotros, de la medicina, para inscribirlo en un ámbito literario.

\section{Bibliografia}

Cáteura. Pedro, Amor y pedagogía en la Edad Media. Salamanca, Universidad, 1986.

Cléugh. James, The Secret Enemy: The Story of a Desease. London. Thames and Hudson [c. 1954].

Dhlicado, Francisco, Retrato de la Lozana Andaluza, ed. Claude Allaigre. Madrid, Cátedra, 1985.

24 [Dioses patrios. a los que se debe Ausonia. Y tú Saturno, padre del Lacio. ¿por quê tu gente ha merecido tanta desgracia?] /bid., p. 42. 
Deilcamo, Francisco, El modo de adoperare el legno de India Occidentale, transcripción crítica de B. M. Damiani, Revista Ihispanica Moderna. New York, 36 (1970-1971), pp. 251-271.

Denvie, Charles Clayton, A Hystory of Syphilis. Springficld, Illinois, Charles Thomas Publisher, 1962.

Fernández de Oviedo, Gonzalo, Stumario de la naural y general historia de las Indias. México, FCE, 1979.

FracAstoro, Girolamo, La Syphilis, poema latino de Gerónimo Fracastor, traducido al castellano $\mathrm{c}$ ilustrado con notas por $D$. Luis María Ramírez y de las Casas-Deza, licenciado en Medicina, caledrático del Instituto Provincial de Córdoba, profesor de Historia y Geografía, individuo correspondiente de la Real Academia de la Historia, de número de la de Buenas Letras de Sevilla y de los Arcades de Roma... Madrid, Imprenta de José M. Ducazal, 1863. $121 \mathrm{pp}$.

García-Vernugo, María Luisa, "La Lozana Andaluza" y la literatura del siglo xvr: la sifilis como enfermedad y como metáfora. Madrid, Pliegos, 1994.

Granjer., Luis S., Vide y obra de López de Villalobos. Salamanca. Universidad, 1979.

Illades, Gustavo, "La Celestina" en el saller salmantino. México, UNAM, 1999.

LóPF7. DE VILLALOBos, Francisco, El sumario de lo medicina con un tratado de las pestfferas bubas. Introducción. edición y notas de María Teresa Herrera. Salamanca, Universidad, 1973.

marquez Villanitiva, Francisco, "Litcratura bufonesca o del "loco" ", NRFH, 34 (1985-1986), pp. 501-528.

Quetel, Claude, History of Syphilis, trad. al inglés por Judith Bradlock y Brian Pike. Cambridge, Polity Press, 1990.

Tremallo, Beth, lrony and Self-Knowledge in Francisco López de Villalobos. New York y London, Garland Publishing. Inc., 1991. Úgol. IN, Francesco A., "Nuovi dati intomo alla biografia di Francesco Delicado", Annali della Facolıà di Lettere e Filosofía della Università degli Studi di Perugia, 12 (1974-75), pp. 445-615. 